\title{
EFFECT OF ORAL ONDANSETRON IN THE PREVENTION OF POSTOPERATIVE NAUSEA AND VOMITING FOLLOWING DIAGNOSTIC LAPAROSCOPY IN DAYCARE PATIENTS
}

\author{
Uma Kuragayala1, Surender Pasupuleti², Bhimeswar M. V ${ }^{3}$ \\ ${ }^{1}$ Associate Professor, Department of Anaesthesiology \& Critical Care Medicine, Osmania Medical College, Hyderabad. \\ ${ }^{2}$ Professor, Department of Anaesthesia, Mallareddy Medical College for Women, Hyderabad. \\ 3 Professor, Department of Anaesthesiology, Gandhi Medical College, Hyderabad.
}

\begin{abstract}
Postoperative nausea with or without vomiting is probably the most common complication of gynaecological diagnostic laparoscopy surgery performed under general anaesthesia. Ondansetron, a 5-hydroxytryptamine receptor subtype 3 (5HT3) antagonist, has been shown to be effective in the prevention and treatment of postoperative nausea and vomiting. Present study is undertaken to evaluate two doses of oral ondansetron in preventing postoperative nausea and vomiting. This double blind, randomized and placebo controlled study in ASA grade I and II daycare gynaecological patients conducted to evaluate the effectiveness of two doses of oral ondansetron (8mg) administered two hours prior to laparoscopy and repeated once 12 hours later. Frequency, severity of nausea and vomiting and side effects of ondansetron were noted. Oral ondansetron is significantly reduced the incidence and severity of post-operative nausea. The frequency and number of emetic episodes were also significantly reduced. Administration of oral ondansetron $8 \mathrm{mg}$ twice a day is a convenient and reliable method to effectively control postoperative nausea and vomiting in daycare patients.
\end{abstract}

\section{KEYWORDS}

Gynaecological Laparoscopy, Postoperative Nausea and Vomiting, Oral Ondansetron.

HOW TO CITE THIS ARTICLE: Uma Kuragayala, Surender Pasupuleti, Bhimeswar M. V. "Effect of Oral Ondansetron in The Prevention of Postoperative Nausea and Vomiting following Diagnostic Laparoscopy in Daycare Patients." Journal of Evolution of Medical and Dental Sciences 2015; Vol. 4, Issue 98, December 07; Page: 16361-16365, DOI: 10.14260/jemds/2015/2418

\section{INTRODUCTION}

Postoperative nausea with or without vomiting is probably the most common complication of surgery performed under general anaesthesia.

Women undergoing gynaecological surgery are particularly at risk of experiencing these problems. In the absence of any antiemetic treatment, the incidence of nausea and vomiting after gynaecological surgery can range from $58 \%$ to $80 \% .^{1}$

Most of the currently used antiemetic drugs (For example antihistaminics, anticholinergics and dopamine receptor antagonists) possess clinically significant side effects such as sedation, adrenergic blockade, dry mouth, dysphoria, restlessness and extrapyramidal symptoms. ${ }^{2}$

The quest for more effective antiemetic drugs without the potential for sedative or extrapyramidal side effects has led to the recent development of a relatively new class of drugs such as ondansetron, granisetron, tropisetron and dolasetron. ${ }^{3}$

Ondansetron, a 5-hydroxytryptamine receptor subtype 3 (5HT.3) antagonist has been shown to be effective in the prevention and treatment of postoperative nausea and vomiting (PONV). It is very popular. Intravenous as well as oral preparations have undergone extensive trials.

Financial or Other, Competing Interest: None.

Submission 18-11-2015, Peer Review 19-11-2015,

Acceptance 27-11-2015, Published 07-12-2015.

Corresponding Author:

Dr. Uma Kuragayala,

Associate Professor, Department of Anaesthesia,

Osmania Medical College/Osmania General Hospital,

Afzalgunj-500 012, Hyderabad.

E-mail: uma.drk@gmail.com

DOI:10.14260/jemds/2015/2418
Oral medications are usually administered thrice a day ( $4 \mathrm{mg}$, $8 \mathrm{mg}$ or $16 \mathrm{mg}$ ). Only one study that we are aware of reported an evaluation of two doses of ondansetron $(16 \mathrm{mg})$ given 8 hours apart. Hence, we planned to evaluate the effect of two doses of Ondansetron (8mg) given 12 hours apart as such as a dosing regimen would be convenient for the daycare patients.

\section{AIM OF THE STUDY}

The aim of this double blind, randomized, placebo controlled study is to evaluate the effectiveness of oral ondansetron (8mg administered twice a day) in preventing postoperative nausea and vomiting in 52 daycare patients undergoing gynaecological diagnostic laparoscopy under general anaesthesia.

\section{MATERIALS AND METHODS}

This was a randomized double blind, placebo controlled study conducted in 52 gynaecological daycare patients, belonging to ASA physical status I or II scheduled to undergo diagnostic laparoscopy with or without chromotubation under general anaesthesia. Informed consent to participate in the study was obtained and the study was approved by the Institute's Ethical Committee.

Obese patients, patients with clinically significant cardiovascular, pulmonary, renal, hepatic, neurological or endocrine abnormalities or patients who had taken antiemetic drugs within 24 hours prior to surgery were excluded from the study.

The patients were randomized to receive orally either $8 \mathrm{mg}$ of Ondansetron hydrochloride dehydrate (Zofer-Natco) or identical looking placebo tablets. The first dose of study medication was administered approximately two hours before induction of anaesthesia and repeated once 12 hours after the 
first dose. Oral diazepam $10 \mathrm{mg}$ was given at the same time as the first dose of study medication to all the patients.

General Anaesthesia was standardized with endotracheal intubation and controlled ventilation using thiopentone sodium, vecuronium, isoflurane and fentanyl.

Postoperative analgesia was provided by oral ibuprofen. Pulse rate, blood pressure and oxygen saturation were monitored. Duration of anaesthesia was noted.

At the end of the procedure, the patient was extubated and shifted to Recovery Room (RR). In the RR patient's pulse, blood pressure and oxygen saturation were monitored. The time at which patients were responding to verbal commands is noted and taken as 'zero' hour for the purpose of evaluation of PONV.

Patients were assessed for nausea by single investigator at the time of recovery and then at $1 \mathrm{~h}, 4 \mathrm{~h}, 12 \mathrm{~h}$ following recovery from anaesthesia. Complaints of nausea or episodes of vomiting between the assessment period were recorded by recovery nurse. Neither the investigator nor nurses involved in recording PONV were aware of the nature of the medication received by the patient.

All the patients were asked whether they experienced any nausea during the assessment period and if the answer was affirmative were asked about the severity which was graded as mild, moderate or severe. Episodes of retching and vomiting were considered as emetic episodes.
At the end of $12 \mathrm{~h}$, patients were questioned about any other complaints during the study period. Metoclopramide $10 \mathrm{mg}$ IV was permitted as a rescue anti-emetic if patient had more than 2 emetic episodes. Patient's feedback is taken during follow-up visit for any nausea and vomiting episodes after 12 hours.

\section{STATISTICAL TOOLS}

Age, weight, changes in vital signs like pulse rate, respiratory rate, systolic blood pressure and diastolic blood pressure were analyzed using student ' $t$ ' test. Pulse rate, respiratory rate, systolic blood pressure and diastolic blood pressure before and after study medication within the groups were compared using paired ' $\mathrm{t}$ ' test.

The incidence of nausea was compared between the groups using Chi-square test and the incidence of vomiting was compared using Fisher's exact probability test. P-value 0.05 was considered statistically significant. A change in vital signs by more than $25 \%$ of the basal values were considered to be clinically significant.

\section{OBSERVATIONS AND RESULTS}

A total of 52 patients were taken for study, 26 of them received placebo, while the other 26 received Ondansetron. All (Both the placebo and the Ondansetron-treated) patients underwent gynaecological diagnostic laparoscopic procedure.

\begin{tabular}{|c|c|c|c|c|}
\hline & \multicolumn{2}{|c|}{ Placebo (n=26) } & \multicolumn{2}{c|}{ Ondansetron (n=26) } \\
\hline & Mean & SD & Mean & SD \\
\hline Age (Years) & 29 & +2.98 & 29 & +4.23 \\
\hline Weight (Kg) & 48.15 & +5.41 & 48.07 & +6.45 \\
\hline Duration of Anaesthesia & 50.77 & +11.29 & 48.85 & +11.25 \\
\hline \multicolumn{6}{|r|}{ Table 1: Age and Weight Distribution and Duration of Anaesthesia } \\
\hline
\end{tabular}

The demographic details (Age and weight distribution) and duration of anaesthesia, which appear in Table 1 showed no significant differences between the mean age and weight of the patients in the two groups. The duration of anaesthesia for placebo group was 30-60 $\mathrm{min}$ (Mean $50.77 \mathrm{~min}$ ) and for ondansetron group was 25-60 min (mean $48.85 \mathrm{~min}$ ).

\begin{tabular}{|c|c|c|c|c|c|}
\hline & & \multicolumn{2}{|c|}{ Placebo Group } & \multicolumn{2}{|c|}{ Ondansetron Group } \\
\hline & & Mean & SD & Mean & SD \\
\hline \multirow{3}{*}{ Pulse Rate* } & Basal & 80 & \pm 7.61 & 81 & \pm 6.78 \\
\hline & After admin. of Drug & 91 & \pm 9.43 & 87 & \pm 13.51 \\
\hline & \% of change & 14.63 & \pm 10.93 & 7.69 & \pm 14.15 \\
\hline \multirow{3}{*}{$\begin{array}{c}\text { Respiratory } \\
\text { Rate† }\end{array}$} & Basal & 21 & \pm 1.49 & 21 & \pm 1.52 \\
\hline & After admin. of Drug & 21 & \pm 1.50 & 21 & \pm 1.63 \\
\hline & \% of change & 3.2 & \pm 5.42 & 3.3 & \pm 5.54 \\
\hline \multirow{3}{*}{$\begin{array}{l}\text { Systolic Blood } \\
\text { Pressure } \neq\end{array}$} & Basal & 119 & \pm 6.60 & 116 & \pm 10.55 \\
\hline & After admin. of Drug & 124 & \pm 8.93 & 121 & \pm 8.31 \\
\hline & $\%$ of change & 5.5 & \pm 7.41 & 4.0 & \pm 9.14 \\
\hline \multirow{3}{*}{$\begin{array}{l}\text { Diastolic Blood } \\
\text { Pressure } \S\end{array}$} & Basal & 75 & \pm 6.98 & 78 & \pm 7.57 \\
\hline & After admin. of Drug & 76 & \pm 7.30 & 78 & \pm 6.52 \\
\hline & $\%$ of change & 1.78 & \pm 12.98 & 1.38 & \pm 11.48 \\
\hline
\end{tabular}

* Pulse (Basal vs after drug admin.), Placebo: $\mathrm{P}<0.001$, Ondansetron: $\mathrm{P}<0.01$, percent of change in pulse (Intergroup comparison) $\mathrm{P}$ values $=0.054$.

† Respiratory Rate-P value not significant.

‡ Systolic Blood Pressure-Significant. Placebo: P - 0.01; Ondansetron: P value not significant percent of change-P value not significant.

$\S$ Diastolic Blood Pressure-P value not significant; percent of change-P value not significant. 


\begin{tabular}{|c|c|c|c|c|}
\hline & \multicolumn{2}{|c|}{ Nausea } & \multicolumn{2}{|c|}{ Vomiting } \\
\hline & Placebo Group $(n=26)$ & $\begin{array}{l}\text { Ondansetron Group } \\
(\mathrm{n}=26)\end{array}$ & Placebo Group $(n=26)$ & $\begin{array}{l}\text { Ondansetron Group } \\
(n=26)\end{array}$ \\
\hline Present & $8(30.77 \%)$ & $2(7.70 \%)$ & $6(23.08)$ & $1(3.85 \%)$ \\
\hline Absent & $18(69.23 \%)$ & $24(92.30 \%)$ & $20(76.92 \%)$ & $25(96.15 \%)$ \\
\hline \multicolumn{3}{|c|}{ P - Value: 0.03} & \multicolumn{2}{|c|}{ * P - Value: 0.04} \\
\hline
\end{tabular}

Ondansetron treatment resulted in a significantly lower incidence of both nausea and vomiting during the study period as shown in the Table 3.

\begin{tabular}{|c|c|c|c|c|}
\hline \multirow{2}{*}{$\begin{array}{c}\text { Assessment } \\
\text { Period }\end{array}$} & \multicolumn{2}{|c|}{ Nausea } & \multicolumn{2}{c|}{ Vomiting } \\
\cline { 2 - 5 } & $\begin{array}{c}\text { Placebo } \\
\text { Group }\end{array}$ & $\begin{array}{c}\text { Ondansetron } \\
\text { Group }\end{array}$ & Placebo Group & $\begin{array}{c}\text { Ondansetron } \\
\text { Group }\end{array}$ \\
\hline $0-1 \mathrm{~h}$ & None & None & None & None \\
\hline $1-4 \mathrm{~h}$ & $5(19.2 \%)^{*}$ & $2(7.6 \%)$ & $3(11.5 \%)^{*}$ & $1(3.8 \%)$ \\
\hline $4-12 \mathrm{~h}$ & $5(19.2 \%)^{*}$ & None & $5(19.2 \%)^{*}$ & None \\
\hline \multicolumn{2}{|r|}{$*$ Two patientshad nausea in both time periods } & $\begin{array}{c}* 2 \text { placebo group patientshad vomiting in } \\
\text { both observation periods }\end{array}$ \\
\hline \multicolumn{2}{|r}{ Table 4: Incidence of Nausea and Vomiting from 0-1h, 1-4h and 4-12h After Recovery from Anaesthesia } \\
\hline
\end{tabular}

The incidence of nausea and vomiting during different study periods over the $12 \mathrm{~h}$ in both the groups were as shown in Table 4. In both the groups, the incidence of PONV in the period of $0-1 \mathrm{~h}$ was zero. During 1-4h of observation, $19.2 \%$ of patients had nausea ( 5 out of 26 ) and $11.5 \%$ of patients had vomiting ( 3 out of 26 ) in placebo group, whereas in the study group only $7.6 \%$ of patients had nausea (2 out of 26 ) and $3.8 \%$ of patients had vomiting (only 1 out of 26 ).

\begin{tabular}{|c|c|c|}
\hline Grade & Placebo Group & Ondansetron Group \\
\hline $0:$ None & $18(69.2 \%)$ & $24(92.3 \%)$ \\
\hline $1:$ Mild & None & $1(3.8 \%)$ \\
\hline $2:$ Moderate & $3(11.5 \%)$ & $1(3.8 \%)$ \\
\hline 3: Severe & $5(19.2 \%)$ & None \\
\hline \multicolumn{2}{|c|}{ Table 5: Severity Grading of Nausea from 0-12h After Recovery from Anaesthesia } \\
\hline
\end{tabular}

The severity of the nausea experienced during the first $24 \mathrm{~h}$ postrecovery is graded as shown in Table 5 . Severe nausea was experienced in none of the patients who received ondansetron, whereas in the placebo group 19.2\% experienced severe nausea.

\begin{tabular}{|c|c|c|}
\hline No. of Episodes & Placebo Group & Ondansetron Group \\
\hline 0 & $20(76.9 \%)$ & $25(96.1 \%)$ \\
\hline 1 & $4(15.3 \%)$ & $1(3.8 \%)$ \\
\hline 2 & $2(7.6 \%)$ & $\mathrm{Nil}$ \\
\hline$>2$ & $\mathrm{Nil}$ & $\mathrm{Nil}$ \\
\hline \multicolumn{2}{|c|}{ Table 6: Number of Episodes of Vomiting from 0-12h After Recovery from Anaesthesia } \\
\hline
\end{tabular}

The number of emetic episodes in both the groups were as shown in Table 6. In placebo group, 15.3\% of patients (4 out of 26) had one emetic episode each and $7.6 \%$ of patients ( 2 out 26 ) had two emetic episodes each. In the ondansetron group, only one patient (3.8\%) vomited once and no patient vomited twice. In both groups, no patient vomited more than twice and hence no patient received rescue anti-emetics.

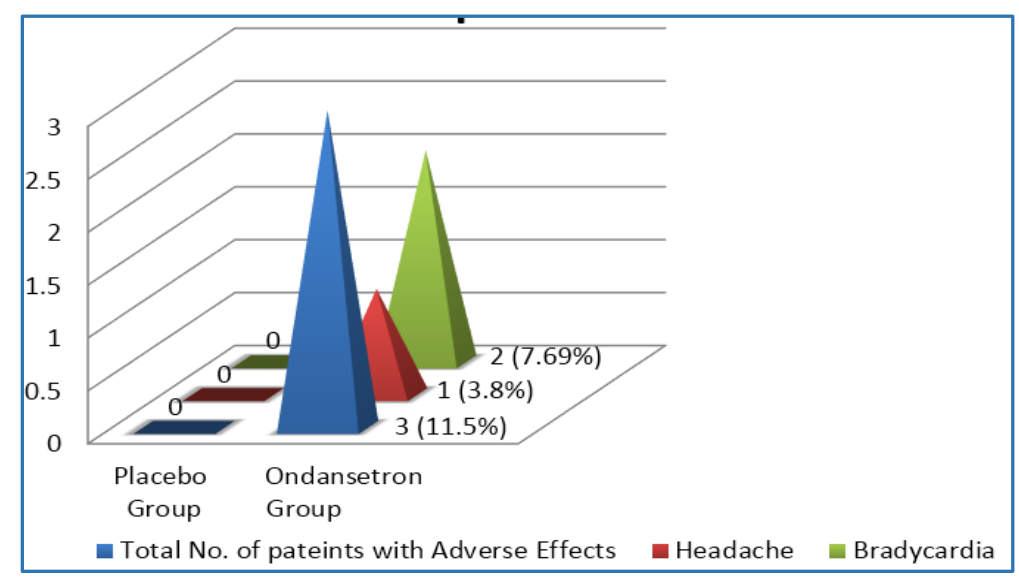

Graph. 1: Incidence of Reported Adverse Effects 
Adverse events were noticed in total three patients in the ondansetron. Out of them two patients showed bradycardia and only one patient complained of headache. No other untoward adverse effects were noticed in this study.

\section{DISCUSSION}

Nausea and vomiting following general anaesthesia has been a distressing problem for patients. Sometimes, it may be the only distressing long lasting memory of the patient's experience regarding general anaesthesia. It increases the recovery time, intensity of nursing care and patient morbidity.

The aetiology of postoperative nausea and vomiting is multifactorial and includes factors both related and unrelated to anaesthesia. The later includes factors such as gender, age and weight.4 Anaesthetic and operative factors include type and duration of operation, type of induction and maintenance agents used.

The reported incidence of PONV following major gynecological surgery varied from $58 \%-80 \% .1,5,6,7$ whereas following gynecological laparoscopy it was reported to be found $36 \%-60 \% .5,8,9,10,11,12$ The benefits of an effective prophylaxis are apparent in such minor procedures, which are currently being done as daycare cases.

An effective antiemetic that could be used to treat nausea and vomiting when they occurred without extending recovery time and that would remain effective for $24 \mathrm{~h}$ following treatment would be a significant asset to the anaesthesiologist armamentarium of drugs. 13

The most commonly used antiemetic medications are antihistamines, anticholinergics and dopamine receptor antagonists. Unfortunately, these drugs cause side effects such as hypotension, sedation, restlessness, dysphoria and extrapyramidal symptoms. ${ }^{11}$

Ondansetron, selective antagonist of $5-\mathrm{HT}_{3}$ receptors is allegedly devoid of activity at dopaminergic, histaminic, adrenergic and cholinergic receptors. The $5-\mathrm{HT}_{3}$ receptor appears to mediate physiologic responses, both in peripheral nervous system and in the vomiting (Emesis) center of central nervous system. ${ }^{14}$

Ondansetron has already proved to be an effective treatment for prevention of nausea and vomiting induced by cancer chemotherapy and radiotherapy. 15

There are several publications indicating the usefulness of ondansetron in preventing PONV, especially in gynaecological laparoscopy. There has been a lot of variability as far as the dose (1mg-16mg), frequency of drug administration (Once a day to thrice a day) and the route of administration (IV or oral).

Oral administration of medications is convenient and advantageous, in that there is no special requirement to maintain intravenous cannulation. It would be advisable if the frequency of administration can be decreased to either once or twice a day. Even though the terminal half-life of ondansetron is around $3.5 \mathrm{~h}$, it was observed that the pharmacological duration of action exceeds the half life. ${ }^{7}$

Hence, we evaluated two 8mg doses of oral Ondansetron given $12 \mathrm{~h}$ apart, the first dose being given $2 \mathrm{~h}$ prior to induction of general anaesthesia. The incidence of PONV was compared with placebo group. Both groups were comparable in terms of age, weight, surgical procedure, anaesthetic technique and duration of anaesthesia.
The incidence of PONV in study was on the lower side in placebo group (30.77\%). The incidence of PONV during $0-1 \mathrm{~h}$ following recovery was nil in both the groups. These findings might have been due to the fact that we routinely avoid the use of nitrous oxide during anaesthesia as some of our gynaecologists use air for peritoneal insufflations.

There was a significant reduction in the incidence of nausea in the ondansetron group during 24 hours following recovery (placebo - $30.77 \%$ vs Ondansetron-7.5\%). In those patients who had nausea, the severity was much less in Ondansetron group (Table 5). No patient in study group had severe nausea, whereas 5 out of 26 patients in placebo group had severe nausea.

In the placebo group incidence of nausea was $19.2 \%$ (5 out of 26) during 1-4 hours of evaluation period as well as during 4-24 hours of evaluation (Table 4). This indicates the need for antiemetic medication for upto 24 hours. In the study group only two patients (7.6\%) had nausea during 1-4 hours and none during 4-24-hour period. This probably indicates the need for the repeat dose of Ondansetron. We could not evaluate for further 24 hours as our patients were discharged the next day. However, all the patients were free of nausea at the time of discharge. There is only one study.15 that reported the usefulness of single dose of Ondansetron. They used 4, 8, $16 \mathrm{mg}$ and reported reduced incidence only with $16 \mathrm{mg}$ Ondansetron. The incidence of vomiting of that population was higher and the reduction is only from $78 \%$ to $66 \%$. Whether a single $8 \mathrm{mg}$ dose could have been effective in our population still needs to be evaluated.

The incidence of vomiting was also decreased significantly in the study group (Placebo-23\% vs Ondansetron-3.85\%). Two emetic episodes occurred in 2 patients of placebo group compared to none in study (Ondansetron) group.

In both the groups, there was a statistically significant increase in pulse rate when compared with the basal values. This may be due to transferring of patients and preoperative anxiety. In the placebo group, the increase is higher $(14.6 \%)$ when compared to study group (7.67\%). However, this difference is not statistically significant. Two patients in Ondansetron group had bradycardia ( $P R<60 / \mathrm{min}$ ). However, they did not require treatment. There is a statistically significant increase in systolic blood pressure in placebo group, whereas an increase in systolic blood pressure in Ondansetron group is not statistically significant. The diastolic blood pressure did not show any statistically significant changes. However, these changes in blood pressure are not clinically significant. There is no significant change in respiratory rate in both the groups.

The adverse effects observed in this study were relatively mild (Two patients had bradycardia and one patient had postoperative headache) in Ondansetron group and did not require any treatment. This is in agreement with other studies, which described only minor side effects.1,16,17

\section{CONCLUSIONS}

Oral Ondansetron (8mg/dose) given two hours prior to induction of General Anaesthesia for Gynaecological Laparoscopy and repeated once 12 hours later had significantly reduced the incidence and severity of postoperative nausea. The frequency and number of emetic episodes were also significantly reduced. Hence, 
administration of oral Ondansetron 8mg twice a day is a convenient and reliable method to effectively control postoperative nausea and vomiting in daycare patients.

\section{REFERENCES}

1. Dupeyron JP, Conseiller C, Levariet $M$, Hemmingsen $C$, Schoeffer P, Pedersan FM, Gribomont B, Kapla LA. The effect of oral ondansetron in the prevention of postoperative nausea and vomiting after major gynaecological surgery performed under general anaesthesia. Anaesthesia 1993 Mar;48(3):214-8.

2. Rowbotham DJ. Current management of PONV. Br J Anaesth 1992. 69 (Suppl 1): 46S-59S.

3. Russel D, Kenny GN. 5-HT3 antagonists in postoperative nausea and vomiting. Br J Anaesth 1992:69 (7 Suppl) 1:63S-68S.

4. Lerman J. Surgical and patient factors involved in postoperative nausea and vomiting. Br J Anaesth 1992;69 (Suppl 1):24S-32S.

5. Madej TH, Simpson KH. Comparison of the use of domperidone, droperidol and metoclopramide in the prevention of nausea and vomiting following major gynaecological surgery. Br J Anaesth 1986;58:884-887.

6. Kenny GN, Oates JD, Lesser J, Rowbotham DJ, Liph, Rust M, Saur P, Onsrud M, Haigh CG. Efficacy of orally administered Ondansetron in the prevention of postoperative nausea and vomiting; a dose ranging study. Br J Anaesth 1992 May;68(5):468-70.

7. Rust M, Cohen LA. Single oral dose Ondansetron in the prevention of postpartum nausea and emesis. The European and US study groups. Anaesthesia 1994 Jan; 49 Suppl: 16-23.

8. Lindblad T, Beattie WS, Buckley DN, Forest JB. Increased incidence of postoperative nausea and vomiting in menstruating women. Can J Anaesth 1989;36:S78.
9. Metter SE, Kitz DS, Young ML, Baldeck AM, Anfelbaum JL, Lecky JH. Nausea and vomiting after outpatient laparoscopy; Incidence, impact on recovery room stay and cost. Anesth Analg 12987;66:S1-S19.

10. Hovorka J, Kortilla K, Erkola O. Nitrous oxide does not increase nausea and vomiting following gynaecological laparoscopy. Can J Anaesth 1989;35:145-148.

11. Pataky AO, Kitz DS, Andress RW, Lecky JH. Nausea and vomiting following ambulatory surgery: are all procedures created equal? Anesth Analg 1988;67:S163.

12. Honkavaara P, Lehtinen AM, Hovorka J, Korttila K. Nausea and vomiting after gynaecological laparoscopy depends upon the phase of the menstrual cycle. Can J Anaesth 1991;38:876-879.

13. Scuderi P, Wetchler B, Sung YF, Mingus M, Dupen S, Claybon L, Leslie J, Talke P, Apfelbaum J, Sharifi-Azad S et al. Treatment of postoperative nausea and vomiting after outpatient surgery with the 5-HT3 antagonist Ondansetron. Anaesthesiology 1993 Jan;78(1):15-20.

14. Chaffee BJ, Tankanow RM. Ondansetron - the first of a new class of antiemetic agents. Clin Pharmacol 1991 Jun;10:430-46.

15. Lesser J, Liph. Prevention of postoperative nausea and vomiting using Ondansetron, a new selective, 5-HT3 receptor antagonist. Anesth-Analg 1991 June;72(6):751-5.

16. Larjani GE, Gratz I, Afshar M, Minassian S. Treatment of postoperative nausea and vomiting with Ondansetron; A randomized, double blind comparison with placebo. Anesth Analg 1991;73:246-9.

17. Gan TJ, Collis R, Hetreed M. Double-blind comparison of ondansetron, droperidol and saline in the prevention of postoperative nausea and vomiting. $\mathrm{Br} \mathrm{J}$ Anaesth 1994;72:544-547. 